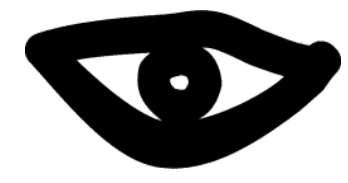

\title{
Aquisição da linguagem: os bebês e o aprendizado heurístico com livros digitais
}

\author{
Language acquisition: babies and the heuristic learning with digital books
}

\author{
Conceição Regina Pinto de Oliveira*, Naiara dos Santos Nobre** \\ *Universidade Federal do Espírito Santo, **Prefeitura Municipal de Guarapari
}

\begin{abstract}
Resumo
Abordamos no texto a aprendizagem heurística de bebês por meio da interatividade, na dinamicidade do século XXI e sua tecnologia. Discutiremos a ideia de criança na primeira infância, que passou de um pequeno adulto à concepção de um ser único de características exclusivas e desenvolvimento neurobiológico superior a qualquer faixa etária, como os estudos científicos contribuíram na construção dessa concepção no decorrer da história, e, também, a importância da literatura na vida dos bebês, explorando as possibilidades de uso do formato de livro digital como potencial recurso pedagógico para desenvolver competências e habilidades nos nativos digitais.

Palavras chave: Aprendizagem heurística, bebês, nativos digitais, novas tecnologias, aquisição da linguagem.
\end{abstract}

\section{Abstract}

We approach the text heuristic learning babies through interaction, the dynamics of the twenty-first century and its technology. Discuss the child's idea in early childhood, which rose from an adult little to the design of a single being unique features and neurobiological development than any age group, as scientific studies have contributed in building this concept throughout history, and also the importance of literature in the lives of babies, exploring the possibilities of using digital book format as a potential educational resource to develop skills and abilities in the digital natives.

Keywords: heuristic learning, babies, digital natives, new technologies, language acquisition.

\section{Um breve histórico da infância, do educar infantil, e de como chegamos até aqui}

Muito se discutiu nas últimas décadas sobre a matrícula e permanência de bebês nas creches. Juntamente com as discussões, temos vivenciado mudanças de concepções e posturas que transformaram o fazer pedagógico e a forma de entender e lidar com crianças em sua primeira infância. Encontramos na obra História Social da Criança e da Família de Philippe Ariès (1981) o lento progresso das concepções de criança e das posturas dos profissionais e autoridades da educação neste aspecto.

Ariès (idem) pontua essas mudanças, desde a Era Medieval, onde milhares de crianças morriam por falta de serviços adequados de higiene e saúde e, quando sobreviviam, eram considerados "adultos em miniaturas", sendo impossível - àquela épocacompreendê-las em seus aspectos particulares.
Adotava-se, por este motivo, uma forma padrão adulta de julgamento e posturas invasivas de instrução que considerava a criança como um livro de páginas vazias a ser preenchido com ideologias e apreensão de códigos que se julgava importantes.

O percurso histórico de investigações do universo infantil nos mostra que a ideia de criança como um ser singular e particular dotado de características específicas, merecedora de cuidados e respeito, começa a ser divulgada e aderida recentemente com o advento da psicanálise e da psicologia infantil. Psicólogos do desenvolvimento como Piaget (1976), Vygotsky (1996) e Wallon (2007) ousaram ao propor a infância em estágios de desenvolvimento e ao defender esta etapa da vida como decisiva e fundamental na formação da personalidade dos indivíduos.

Com o advento dessas novas ideias herdadas da psicologia, políticas públicas foram criadas para contemplar e assegurar diretos a crianças nas mais diversas faixas etárias, embora que de maneira lenta e exigidas pela sociedade organizada. A Constituição da República Federativa do Brasil, que data de 1988, em seu $205^{\circ}$ artigo assegura o direito à Educação a todos os indivíduos como dever do Estado e da família, visando o desenvolvimento pleno deste indivíduo e seu preparo para o trabalho e para a cidadania. O Estatuto da Criança e do Adolescente (ECA, 2001), em seu artigo 53 reforça o direito das crianças à educação pública. A Lei de Diretrizes e Bases da Educação Nacional, de $\mathrm{n}^{\circ}$ 9394/96 (LDB) assegura o direito e a matrícula obrigatória das crianças aos sistemas de ensino a partir dos 4 anos de idade, ampliando o acesso das crianças pequenas às instituições educativas. A Lei federal $\mathrm{n}^{\circ}$ 12.796/2013 afirma ainda que "[...] a educação infantil (EI), primeira etapa da educação básica, tem como finalidade o desenvolvimento integral da criança de até 5 anos, em seus aspectos físico, psicológico, intelectual e social, complementando a ação da família e da comunidade".

Em seus estudos, Moss (2011) ressalta o art. 28 da Convenção sobre os Direitos da Criança da Organização das Nações Unidas (ONU), que reconhece o direito à educação desde os primeiros anos de vida, dando-lhe a interpretação de que esse direito se inicia com o nascimento, intimamente ligado ao direito das crianças pequenas ao máximo desenvolvimento. Vinculado ao reconhecimento, o atendimento educacional com qualidade se coloca como um desafio ao poder público, principalmente na efetivação da 
expansão do atendimento às crianças pequenas da educação infantil.

Nas palavras de Campos (2011), o direito à educação inclui também a exigência de qualidade e o respeito às necessidades da criança em cada fase do seu desenvolvimento: o direito à brincadeira, à atenção individual, ao aconchego e ao afeto, ao desenvolvimento da sociabilidade, assim como o direito à aprendizagem e ao conhecimento. (CAMPOS, 2011).

Contudo, a obrigatoriedade de matrícula das crianças nas instituições educativas aos 4 anos gerou alguns pontos de tensão no processo de implantação dessa nova faixa de obrigatoriedade, que deverá efetivar-se por completo até o ano de 2016. À primeira vista, pode parecer que a ampliação da obrigatoriedade escolar seja uma boa notícia, especialmente num país como o Brasil, em que ainda persistem muitas dificuldades de acesso e permanência na escola. Entretanto, a Emenda Constitucional 59/2009, ao tornar parte da educação infantil obrigatória (a pré-escola) e afirmar que o acesso obrigatório à educação deve ser priorizado pelos gestores públicos, origina uma tensão sobre a frágil e desestruturada etapa da creche. Nos municípios com poucos recursos financeiros, a obrigatoriedade a partir dos quatro anos pode significar desestímulo à oferta de vagas em creches, além de comprometer a qualidade e melhoria do atendimento daquelas já existentes.

No Brasil, houve um tempo em que a creche espaço educacional de atendimento à primeira infância - tinha um caráter exclusivamente assistencial, de guarda, cuidados e proteção para crianças de famílias trabalhadoras de baixa renda. Hoje o cenário se modificou. Em sua expressiva maioria, as instituições de educação infantil buscam contemplar o cuidar e o educar como instâncias indissociáveis no atendimento às crianças pequenas comprometidas com 0 desenvolvimento integral das crianças.

O Plano Nacional de Educação (PNE) para o decênio 2011-2020, em vigor no Brasil, traz como primeira meta universalizar até 2016 o atendimento escolar da população de 4 e 5 anos e ampliar até 2020 a oferta de educação infantil, de forma a atender $50 \%$ da população de até 3 anos. Colocada nesses termos, a meta vem reforçar a fratura provocada na EI pela EC 59/2009. Ao colocar a etapa da creche como facultativa, chama as atenções para a pré-escola agora obrigatória, e o segmento anterior perde força de pressão, sob todos os aspectos. À medida que a creche se expandir, se os processos educacionais não assegurarem uma sequência harmônica entre as etapas da EI, pode se repetir, na sua passagem para a préescola, o fenômeno da ruptura existente entre a préescola e o ensino fundamental em muitos sistemas de ensino (BRASIL, 2010).

Compartilhamos do pensamento de Moss (2011) ao associarmos essa ruptura na passagem das crianças da EI para o ensino fundamental à premissa de que a educação infantil e a escola muitas vezes provêm de tradições muito diferentes, têm culturas muito diferentes, e que essas tradições e culturas se expressam em concepções, valores e práticas muito diferentes. De maneira geral, enquanto a educação das crianças de 0 a 3 anos se revestiu de cunho filantrópico/assistencialista e as pré-escolas assumiram um caráter educativo/pedagógico - preparar as crianças para o ingresso na vida escolar -, por sua vez, a escola é, tradicionalmente, o espaço instituído para a transmissão de conhecimento, desenvolvendo práticas pedagógicas muito diversas das que encontramos na EI.

Essa ruptura, seja dentro da própria EI ou na passagem das crianças da EI para o EF, se coloca como um ponto de tensão entre a garantia legal do direito das crianças a uma educação universalizada e de qualidade e o que se tem verificado dentro dos sistemas municipais de educação. No entrelaçamento dos textos legais que fundamentam a EI como direito da criança e das famílias e dever do Estado e a realidade social contemporânea, a demanda por instituições de Educação Infantil se justifica e se consolida como uma prioridade a ser atendida pelos municípios brasileiros, de acordo com as definições constitucionais e legais vigentes.

Além de todas as mudanças na forma de atendimento educacional às crianças pequenas, destacamos 0 contexto social atual em que elas vivem. Estamos em uma sociedade de informações prontas e rápidas, do advento das mídias e das tecnologias da informação e comunicação que sorrateiramente invade a vida das classes mais altas as mais baixas. Neste cenário, vemos uma educação fragilizada pela constante tentativa frustrada e ineficaz de efetivar os processos de ensino e de aprendizagem como algo mecânico, retrógrado, baseado quase sempre na repetitividade, memorização e exposição de conteúdos que o aluno já obteve por outros meios, como pela TV ou pela internet.

A formação crítica da criança como desafio da escola, pressupõe uma renovação da concepção da criança, como também dos processos de ensino e aprendizagem, suas implicações técnicas, meios e instrumentos facilitadores da produção de conhecimento. As novas tecnologias da informação e comunicação (TICs) - são, sem dúvida, instrumentos formativos para a aprendizagem significativa no cenário educacional atual. Logo, não devem ser utilizadas apenas no ensino de pessoas já letradas. Nasce a necessidade de incorporar tais tecnologias no aprendizado de crianças e bebês, considerados por Mark Prensky (2001) como nativos digitais.

\section{O bebê, seu desenvolvimento, a linguagem e a precoce interação com as tic's}

Nesta pesquisa, compreenderemos o estudo de crianças de 12 a 24 meses, denominando-as bebês, segundo o conceito de Parreiras (2012) quando afirma que pediatras, psiquiatras, psicanalistas, costumam considerar que uma criança com até 24 meses é um bebê.

Bebês são seres dependentes para satisfazerem suas necessidades básicas de sobrevivência, mas desde cedo aprendem a comunicar-se com os adultos para as satisfazer, por meio de coros e balbucios, à sua vontade. Após o desmame - aproximadamente a partir 
do $8^{\circ}$ mês - o bebê, simultaneamente à construção de esquemas motores, também concentra sua energia na construção dos pensamentos, relacionamentos, jogos e suas regras, jogos simbólicos, entre outras atividades. É exatamente nesta etapa que os bebês começam a imitar seus pais e adultos que o cercam, os usando como modelos de comportamento.

Partindo do pressuposto que o bebê explora à sua maneira o mundo ao seu redor, na sociedade atual há que se notar que os objetos de manipulação e descoberta já não são mais os mesmos de décadas atrás. Com a crescente evolução das TIC's, objetos como smartphones, tablets, computadores, smartTV's tem sido utilizados pelas mais variadas classes sociais. E é claro que esta mudança de cenário tem refletido nas posturas emocionais, biológicas e nos esquemas que as crianças constroem em suas interações com os objetos e pessoas que as rodeiam.

Conforme afirma Wallon (2007), este estágio devemos chamar de Estágio Impulsivo Emocional e está ligado à afetividade com as pessoas e à interação com o meio. Piaget (1976) propõe e define este estágio como Estágio Sensório-Motor, que prevalecerá até o terceiro ano de vida aproximadamente e está voltado a exploração do mundo físico que o cerca. É natural, por esse motivo, que o bebê rejeite ajuda em sua exploração com o mundo físico. O espaço onde o bebê convive e os objetos disponíveis para sua exploração devem ser bem pensados e planejados de modo que o bebê tenha variedade de cores, formas e tamanhos para explorar com a devida segurança, em especial nas instituições educativas que os atendem. Destacamos que neste Estágio Impulsivo Emocional o bebê vai deixando ao poucos o brincar mecânico e repetitivo e o transforma em um brincar construtivo, no qual os jogos e objetos já começam a adquirir caráter imaginativo. Uma peça retangular do bloco de construção, por exemplo, pode tornar-se, na imaginação do bebê, um telefone móvel que com balbucios tenta falar com alguém na linha. O mesmo retângulo pode tornar-se um carro a ser arrastado pelo chão, ou um avião a ser arremessado pelo ar. É importante que nesta etapa o adulto mediador incentive a espontaneidade do bebê, e não o limite a rotinas escolares cansativas $\mathrm{e}$ burocráticas.

No dizer de Piaget (1976), esquema é a estrutura que se dá na troca do organismo com o meio. Esses esquemas são produzidos pelas crianças, sem auxílio de qualquer ajuda adulta, somente pelas interações com os objetos e meios. Palanga, citando Chiarottino, acrescenta que o esquema é a condição primeira da ação, ou seja, da troca do organismo com o meio. Ele é engedrado pelo funcionamento geral de toda organização viva, a adaptação. O organismo com sua bagagem hereditária, em contato com o meio, perturbase, desequilibra-se e, para superar esse desequilíbrio, ou seja, para adaptar-se, constrói esquemas. (Chiarottino apud Palanga, 2001)

Quando um bebê tenta segurar um objeto circular nas mãos, ele constrói um esquema de segurar objetos circulares. Posteriormente ele percebe que o esquema pode ser modificado para segurar um objeto retangular, percebendo suas formas e arestas e assim sucessivamente.

Maria Montessori apud Röhrs (2010) diz que a mão é um órgão composto de estrutura delicada e complexa que permite a inteligência estabelecer relações com o ambiente de forma especial. Pode-se dizer que o homem transforma o ambiente ao seu redor sob a orientação da inteligência se apoderando do ambiente com as mãos.

Quando um bebê de 10 a 24 meses manipula um celular ou tablet com tecnologia touchscreen, mesmo sem auxílio de um adulto, ele cria o esquema de deslizar os dedos por sobre a tela, percebendo a interação com o objeto por meio de cores, sons e movimentos que estes objetos produzem.

No segundo ano ano de vida, as crianças sentem um grande impulso de explorar e descobrir por si mesmas a maneira como os objetos se comportam no espaço quando são manipulados por elas. Elas precisam de uma ampla gama de objetos para fazer esse tipo de experiência, objetos que sejam constantemente novos e interessantes, os quais certamente não podem ser comprados em um catálogo de brinquedos. (Goldschmied e Jackson, 2006)

Estes objetos dos quais Goldschmied e Jackson (2006) falam são objetos do cotidiano e da vida social dos bebês, desde tapetes em que engatinham até os computadores que os pais usam. Ao manipular tais objetos, sendo o livro digital um desses, o bebê se adapta e de forma autônoma e espontânea e descobre por si, possibilidades de interação.

A observação de crianças dessa idade lembra a antiga história de Arquimedes no banho. Quando descobriu a lei de deslocamento da água devido ao volume do seu corpo, diz-se que ele saltou de dentro da banheira gritando exultante: "Eureka - Encontrei!". A palavra rea eurisko, da qual é derivada nossa palavra "heurístico", significa "serve para descobrir ou alcançar a compreensão de algo" isso é o que crianças pequenas fazem espontaneamente, sem qualquer direcionamento dos adultos, desde que tenham os materiais com os quais efetuarão suas explorações. Longe de perder a habilidade de concentrar-se, torna-se claro que, dadas as condições e os materiais corretos, a criança em seu segundo ano de vida pode desenvolver sua concentração de uma nova forma. (Goldschmied e Jackson, 2006, p.148)

Aliado ao motor da criança está o desenvolvimento da sua linguagem. Feldman e Sears (1981) afirmam que o desenvolvimento cognitivo na primeira infância é subjetivo e influenciado por fatores hereditários, genéticos, ambientais e que as capacidades mentais de uma criança antes do desenvolvimento da linguagem assemelham-se as de um chipanzé, concentrando-se em controlar os movimentos do corpo, locomover-se e explorar o ambiente.

Sendo assim, o desenvolvimento linguístico é um momento crucial que marca a primeira infância. Diz Papalia que o desenvolvimento da linguagem ilustra a interação de todos os aspectos do desenvolvimento. À 
medida que as estruturas físicas necessárias para associar som e significado estão ativadas, a interação social com adultos introduz os bebês à natureza comunicativa da fala. (Papalia, 2006, p. 213)

Antes mesmo de poder falar, a criança já se comunica e expressa suas vontades e sentimentos por meio do choro, balbucios e imitação de sons, todos eles denominados fala pré-linguística. Durante esse período, a capacidade de perceber diferenças entre os sons é adquirida e se torna essencial para o desenvolvimento da linguagem. Aos seis meses de idade, um bebê já reconhece os fonemas de sua língua e, antes de atribuírem qualquer significado aos sons, já reconhecem padrões sonoros que ouvem com frequência, entendendo e apreendendo regras fonológicas.

Aproximadamente no nono mês de vida, outro tipo de linguagem surge: a gestual. Apontar para um objeto demonstrando querer pegá-lo é um exemplo de gesto simbólico aprendido espontaneamente pela criança. Goodwyn e Acredolo (1988), citados por Papalia (2006), afirmam que muitos pais demonstram preocupação ao encorajar gestos por acreditar ser prejudicial no desenvolvimento da fala, enquanto, na verdade, o gesto representa uma vantagem linguística significativa no tocante em que é um correspondente à palavra que será aprendida.

A fala linguística inicia-se entre o décimo e o décimo quarto mês. Neste período, começam a ser utilizadas pelas crianças expressões verbais que comunicam um determinado significado: as primeiras palavras. No entender de Papalia,

Os bebês compreendem muitas palavras antes de poderem utilizá-las; ou seja, seu vocabulário passivo desenvolve-se mais rapidamente e é maior do que seu vocabulário ativo. As primeiras palavras que a maioria dos bebês compreendem são aquelas que eles tendem a ouvir com mais frequência: seus próprios nomes e a palavra não, assim como palavras com significado especial para eles. (Papalia, 2006, p. 215)

$\mathrm{O}$ repertório verbal de um bebê nessa idade tende a ser limitado, por vezes até monossilábico, composto por holofrases. Todavia, até os dezoito meses o vocabulário de palavras isoladas aumenta gradativamente podendo dar um salto de cinquenta até quatrocentas palavras. A partir dos dezoito meses, as crianças demostram competência na sintaxe, ou seja, nas regras para a formação de sentenças na sua língua. No início, omitem palavras funcionais, mas já formam frases com sentido. Aos três anos de idade, uma criança já pode ser considerada fluente em sua língua materna.

Bakhtin evidencia em seus trabalhos uma epistemologia linguística baseada na constante interação entre o ser humano, a sociedade e a linguagem. Evidencia, o autor, a natureza sociológica da linguagem, afirmando que "a língua vive e evolui historicamente na comunicação verbal completa." (Bakhtin, 1986, p.124).

Os bebês, objeto de estudo desta pesquisa, estão em constante contato com enunciados e enunciações considerados por Bakhtin como o processo básico da interlocução - carregadas histórico e culturalmente por valores e interesses. Eles vivem imersos num contexto linguístico repleto de sentidos e à medida em que interage com os outros e se apropria da linguagem.

A língua materna - a composição de seu léxico e sua estrutura gramatical -, não a aprendemos nos dicionários e nas gramáticas, nós a adquirimos mediante enunciados concretos que ouvimos e reproduzimos durante a comunicação viva que se efetua com os indivíduos que nos rodeiam. Assimilamos as formas da língua somente nas formas assumidas pelo enunciado e juntamente com essas formas. As formas da língua e as formas típicas dos enunciados, isto é, os gêneros do discurso, introduzemse em nossa experiência e em nossa consciência juntamente e sem que sua estreita correlação seja rompida. Aprender a falar é aprender a estruturar enunciados (porque falamos por enunciados e não por orações isoladas e, menos ainda, é óbvio, por palavras isoladas). Os gêneros do discurso organizam nossa fala da mesma maneira que a organizam as formas gramaticais (sintáticas). (Bakhtin, 2003, p. 301).

Entende-se que, se falar envolve compreender e organizar enunciados e depende de estruturas lógicas dos gêneros do discurso, torna-se necessário oportunizar ao bebê o contato com a maior variedade de gêneros possíveis para que de forma assistemática ele compreenda as diferenças e semelhanças genéricas que existem entre textos e suas possíveis aplicações nas interações verbais. Bakhtin (2003) afirma que a variedade dos gêneros do discurso são infinitas pois a realidade da atividade humana é inesgotável. Cada atividade humana compreende um repertório grande de gêneros do discurso, que se desenvolve e fica cada vez mais complexa. O próprio diálogo cotidiano, apresenta uma variedade de temas, situações e protagonistas que se desencadeiam em enunciados diversos a cada momento. As cartas oficiais como necessidade de comunicação, os modos literários como o romance, um conto, uma poesia, e os documentos oficiais de todas as ordens também compreendem gêneros do discurso presentes no cotidiano do homem moderno.

Os livros em formatos digitais podem contemplar, simultaneamente, inúmeros gêneros do discurso. As aplicações programáveis nos mais diferentes formatos, como JAVA e FLASH, abrem um campo textual de possibilidades quase infinitas. Consideramos que este recurso é um importante aliado à aquisição da linguagem pelas crianças pequenas pois além de oportunizar o acesso aos gêneros do discurso possui ainda a vantagem da interatividade, característica das novas tecnologias que propicia a constante adaptação e construção de novos esquemas. Nos formatos digitais, os livros permitem uma leitura ativa permeada por estímulos audiovisuais diversos, mutáveis de acordo com os comandos dados.

\section{Os bebês e os livros}

Sugerir leitura e literatura a bebês causa sempre estranhamento e insegurança em quem os rodeia. A pergunta que geralmente se faz é: porque ler para crianças que sequer ainda falam?

Reyes (2010) apresenta um ponto de vista acerca deste questionamento. Os diversos enfoques teóricos 
sobre a primeira infância (psicologia, pediatria, neurociências, pedagogia) concordam que o período entre 0 e 3 anos é o mais favorável à maturação e à aprendizagem.

As pesquisas da neurologia por exemplo, comprovam que a maleabilidade ou a plasticidade do cérebro infantil é praticamente ilimitada e que durante a etapa intrauterina e os três primeiros anos de vida se registram um crescimento neurônico acelerado e uma proliferação inusitada de conexões entre os neurônios. O cérebro é composto por bilhões dessas células que se unem através de conexões ou redes neuronais sinapses - , em um processo conhecido como "rede cerebral". O cérebro do bebê tem um número muitíssimo maior de neurônios que o do adulto e está habilitado a estabelecer inumeráveis conexões, em razão das experiências que o meio the oferece. No entanto, como nenhum ser humano tem uma qualidade tão ampla de experiências para tal "capacidade instalada", no início muitos desses circuitos disponíveis não são usados. Os neurônios estimulados com maior frequência continuam funcionando e os que não o são perdem sua sinapse. (Reyes, 2010, p. 26)

Sendo assim, ler para um bebê estimula circuito neurais relacionados a linguagem e abstração que não seriam ativados sem o estímulo. Alem disso, é importante lembrar que os bebês são seres culturais e sociais, que interagem com o meio e as pessoas a sua volta. A todo momento o bebê toca, vê, sente e observa o mundo e os textos a sua volta. Reforçamos a importância de que o trabalho pedagógico com bebês inclua a apresentação de livros nos mais diversos formatos para que sejam manipulados à sua vontade. No contexto atual do mercado editorial brasileiro, centenas de livros são publicados com diferentes texturas, espessuras, cheiros, sons, imagens e tamanhos, facilitando aos professores a utilizaçãode livros no cotidiano do trabalho com bebês.

Papalia (2006) apresenta outro argumento que defende a leitura para bebês. Quando afirma que o vocabulário passivo se forma muito antes do que o vocabulário ativo - aquele que é falado - nas crianças, defende, ao mesmo tempo, que possibilitar o acesso dos bebês aos livros é permitir que seu vocabulário passivo seja desenvolvido e por consequência, posteriormente, seu vocabulário ativo seja ampliado. Mas, para isso, é necessário selecionar os livros que serão utilizados com crianças pequenas e verificar se estão adequados à essa faixa etária.

Quando selecionamos um livro que será utilizado por bebês é indispensável observar as suas características materiais que nos permitam uma prática didática segura e favorável. Um livro infantil voltado para bebês deve ter fácil manuseio, ter capas e folhas rígidas, de preferência com as vértices arredondadas, peso leve e conteúdos concisos adequados ao vocabulário de leitura dos bebês, que venham a lhes permitir a apreensão completa do enunciado contido no texto.

Parreiras (2012) concorda que num livro para bebês, não deve haver muitas explicações, mas coisas sugeridas, brincadeiras, surpresas, uso de um texto enxuto desprovido de excessos de adjetivos e advérbios". A interatividade implícita no ideal de livro infantil preconizado pelo autor não poderia ser melhor encontrada do que nos formatos digitais dos livros. Com a acentuada evolução dos softwares e aplicativos, cada vez mais surgem conteúdos infantis como jogos de cunho educativo que estimulam a oralidade, a coordenação motora, entre outras competências.

Pode-se encontrar na nuvem de dados, que é a internet, livros infantis em diferentes formatos midiáticos digitais, entre eles: áudio-livros, livros em vídeo, livros em slides e movimentos, livro-sgame interativos, etc. Todos esses formatos digitais de livros podem ser 'materializados' por diversos e diferentes instrumentos como: computadores, tablets, smathphones que permitem uma interação leitor-livro muito íntima, intensa e lúdica. As formas de interagir com os livros digitais são ilimitadas no passo que cada formato midiático apresenta suas possibilidades e características próprias.

Quando o livro permite à criança brincar, se colocar na história, criar fantasias, se subjetivar, ele é como um brinquedo. Isso porque o brinquedo é o primeiro objeto cultural introduzido na vida do bebê. Por meio do brinquedo, ele se conhece, se comunica, interage com o meio ambiente e com os outros. E por meio do livro, pode se colocar, pode imaginar, pode se divertir, pode compartilhar experiências com outras pessoas. (Parreiras, 2012)

Assim, o livro digital materializado por qualquer que seja o instrumento tecnológico, quando permite à criança uma interação verdadeira e lúdica, torna-se um brinquedo, objeto de desejo e prazer que a criança procurará manipular novamente em outros momentos para entreter-se sem ao menos sentir a intencionalidade pedagógica contida no livro. Dessa forma, como defendemos na educação infantil: a criança aprende brincando.

Os bebês e a ação do aprendizado heurístico com livros digitais: pesquisa de campo

Ao pensar nos processos de ensino e aprendizagem no século XXI, não podemos desconsiderar o contexto histórico e as características do momento em que vivemos. Há que se notar que os cenários e percepções em que se vive nos dias atuais, mudaram bruscamente em poucas décadas. As informações chegam cada vez de forma mais rápida aos indivíduos em gamas cada vez maiores de conteúdos; as televisões, que antes não tinham cor e utilizavam sons monofônicos, agora apresentam imagens em alta definição e tecnologia superior de som estéreo; ligações para outros estados e para o exterior podem ser feitas de forma gratuita pelo skype (aplicativo de mensagens instantâneas), enquanto a duas décadas atrás, ligar para o exterior era inviáveis pelo alto custo. Tantas modificações nos cenários e informações modificaram nos indivíduos sua forma de percepção do mundo e novas formas de aprendizagem. A interatividade, considerada uma característica das TIC's, auxilia nessa modificação de percepção, contribuindo para o aprendizado heurístico, provocando a constante desequilibração e equilibração 
do indivíduo no dinamismo presente no contexto do século XXI.

Moran (1995) afirma que as inovações tecnológicas modificam os padrões de como se lida com a realidade e criam novos pontos de vista modificando nossas expectativas. Uma das mudanças que as inovações tecnológicas causaram foi a necessidade de comunicarse por meio dos sons, imagens e diferentes textos integrando mensagens e tecnologias multimídia. Esse novo padrão de necessidade de comunicação, perpassa o limite do casual e adentra também no educacional, já que geram novas formas de aprendizagem e por consequência exigem novas formas de ensino.

As crianças, considerada por Prensky (2001) como nativos digitais, são nascidas imersas num contexto voltado para as tecnologias da comunicação e informação. Os nativos digitais possuem características específicas como a habilidade de multitarefas: eles conseguem ouvir músicas, enviar e receber arquivos pela internet, conversar com os amigos simultaneamete, sem que uma tarefa interfira na outra. Essas habilidades interferem em como esse novo perfil de indivíduo aprende e se motiva.

Talley, Lance e Lee (2007) afirmam que existe na criança uma motivação intrínseca para o uso de computadores, que evidencia-se pelo fato de que as crianças passam um longo tempo focadas em atividades no computador, considerando o tempo que passam focadas com outras atividades. Para elas, manipular instrumentos digitais como computadores, tablets e smarthphones não é somente um ato prazeroso como uma ação automática.

Para afirmar isso, Mouza (2005) em um estudo implementando a tecnologia por cem dias numa préescola nos Estados Unidos da América, chega a conclusão que todas as crianças na primeira infância submersas a este novo tipo de currículo e métodos, baseados no uso das tecnologias de forma planejada e atrelada ao cotidiano escolar, apresentaram resultados significativos em motivação para aprender matemática, leitura e escrita.

Essa motivação se dá ao fato de que o ambiente em que são inseridas, é rico em estímulos e interações multimídias e tudo o que é analógico, monocromático e monoaural tende a ser limitado e sem atrativos a essa nova geração. Prensky (2001), confirma que a nova educação, tem de se adaptar às características dos novos tempos, e isso pressupõe a integração das novas tecnologias e novas mídias no despertar da motivação ao aprendizado do novo perfil de aluno.

Partindo dessa premissa, utilizando instrumentos digitais com mídias de livros, realizamos uma pesquisa de campo exploratória qualitativa em uma escola da rede pública do município de Guarapari, com o objetivo de analisar os usos de instrumentos digitais com mídias de livros como recursos pedagógicos potencializadores de aprendizagens significativas por bebês. Os procedimentos metodológicos de produção de dados foram a observação formal e observação participante durante um período de tempo de quatro meses, com registro das observações em diário de campo.
O trabalho foi desenvolvido com um grupo de quinze bebês entre 6 a 24 meses de idade. As crianças compunham um grupo denominado Berçário I, atendidas na creche "Jardim" (nome fictício), situada em bairro de classe popular (baixa renda). As atividades foram registradas durante os momentos de contação de histórias com apoio de livros em formatos digitais materializados em um smarthphone com tela touchscreen de 5 polegadas. Para esta pesquisa foram escolhidos dois aplicativos de livros: "O homem biscoito" e "Onde está a minha mãe". Ambos os aplicativos, distribuídos gratuitamente para iOS ou sistema Android, exigem do leitor a interação com o deslizar dos dedos por sobre a tela com a finalidade de dar continuidade à história em formato de slides semiestáticos e narração. Esses livros compreendem histórias consideradas por nós longas, exigindo da criança concentração e rítmo de leitura.

Durante as observações, registramos as mais variadas reações dos bebês no primeiro contato assistido com o smartphone, após ouvirem a história contada pela professora que manipulava o aplicativo foi permitido que manipulassem o objeto. A primeira surpresa ao iniciar essa prática pedagógica foi a iniciativa dos bebês em segurar firmemente e olhar para o smarthphone e não colocar diretamente na boca como costumam fazer com a maioria dos objetos, comportamento natural de sua fase oral, segundo Freud (1976).

Nas descrições abaixo, todos os nomes dos bebês são fictícios, vinculados ao compromisso ético desta pesquisa na garantia do anonimato de todos os sujeitos participantes do estudo:

- Matheus - 13 meses - sentado no tapete emborrachado, deixou o objeto cair. Apanhou de volta em suas mãos, com os desenhos do aplicativo de cabeça para baixo, atento ao som que emitia, apertava os botões laterais e tocava a tela a todo instante, não esperando a finalização das etapas da história.

- Patrícia - 14 meses - olhou para a tela completamente concentrada e girava o smarthphone procurando por onde saía a narração e os sons. Ao término da narração do primeiro slide da história, colocou o smarthphone no ouvido em posição de chamada e balbuciou algo como se estivesse falando com alguém pelo telefone. Quando a história voltou a ser narrada após aluns minutos, voltou a concentrar-se nas imagens e no som.

- Melissa - 18 meses - sentada, segurou o smarthphone na posição horizontal como era esperado. Ouviu atentamente a primeira parte da narração e olhou para a professora como se esperasse algum comando. Foi estimulada a deslizar o dedo por sobre a tela e após isso, sempre que a narração parava usava o mesmo esquema motor para continuar a história. Antes do final da história de 16 slides, perdeu o interesse no objeto, levantou-se e pegou uma bola.

João - 18 meses - Segurou o smarthphone com as mãos e apertou todos os botões e teclas até sair do aplicativo. A professora colocou novamente a história. Observava os desenhos interessado, mas muito 
ansioso não esperava o final da narração para interagir com a tela.

- Francisco - 20 meses - Segurou o smarthphone com as duas mãos na posição horizontal e observou com curiosidade as imagens e narração, mas logo quando a primeira parte do áudio cessou, abandonou o objeto no chão. Estimulado pela professora a pegar novamente o objeto, concentrou-se novamente à narração e as imagens, mas não demorou a perder o interesse pela história, preferindo manipular o objeto desordenadamente para ouvir sons diferentes.

Observamos que os bebês, no decorrer da pesquisa, não se limitaram a ouvir os sons que o aplicativo produzia. Ao manipular os livros digitais eles produziam sons e pequenas palavras em resposta a sua interpretação. Alguns bebês balbuciavam fonemas, outros com palavras curtas respondiam aos estímulos. Ao aparecer um desenho animado de um menino na tela, um dos bebês dizia "neném", demonstrando reconhecer a semântica social da imagem apresentada. Interagir com os livros digitais, nessa perspectiva, deixa de ser apenas uma observação de instrumentos e aplicativos, pois insere a criança pequena na esfera da linguagem como sistema de representação, no qual já começou a expressar-se e compreender a expressão de seus interlocutores.

É necessário, aqui, salientar que a língua natural é uma forma de representação do mundo e seus eventos. Ferrarezi Jr. (2008) diz que usamos a língua para 'criar' mundos que são representados também pela língua. Essa representação e criação ocorrem, porém, somente em contextos culturais nos quais as representações são compartilhadas e por esse motivo, o que foi representado pode ser compreendido.

Ao observar os livros digitais propostos na língua materna, os bebês entraram no sentido compartilhado de uma língua, reagindo a ela de forma ativa, construindo saberes e 'criando' mundos de significados.

Salienta-se que apesar do reforço pedagógico e do planejamento das ações para esta pesquisa, as reações dos bebês ao manipular os objetos digitais foi automático e espontâneo confirmando o que diz Goldschmied e Jackson (2006) sobre a aprendizagem heurística da criança, não sendo necessária a intervenção do adulto para que se desenvolva.

No decorrer da pesquisa com duração de quatro meses, outros livros digitais, além dos que foram citados nesta pesquisa, foram utilizados incluídos em sequências didáticas e no final, todos os bebês de 13 a 20 meses já dominavam os esquemas motores necessários para interagir com os livros digitais, tais como apertar os botões necessários ou deslizar o dedo na tela para que o aplicativo continuasse a ser exibido e em todas as explorações aconteceram interações linguísticas que contribuíram para a aquisição da língua materna.

\section{Concluindo}

No decorrer dessa pesquisa, foram observadas as características do desenvolvimento integral da criança e sua linguagem, apoiadas pela revisão de literatura.
Entendeu-se que a aquisição da linguagem como uma dimensão representativa e cultural pelos bebês dá-se por meio da interação com outros e com objetos culturais contidos de textos e significados.

Consideramos que o livro infantil é fundamental na aquisição da linguagem pela criança, e deve, segundo Faucher apud Coelho (2000) provocar o conhecimento de objetos ou seres do cotidiano da criança a serem designados pelo nome de forma oral. Os livros tem a capacidade de oportunizar à criança o convívio com a imagem associada à palavra nomeadora ligando a percepção visual à palavra correspondente.

Considerando as características da época em que estamos inseridos, salientamos a importância de moldar as técnicas e filosofias da educação de acordo com as tendências e novos tipos de aprendizagens e motivações intrínsecas ao novo perfil de criança, nascida em meio às novas tecnologias e consideradas como nativas digitais. (Prensky, 2001), por esse motivo, utilizamos nas práticas, livros em formato digital materializados em smartphones, objeto do cotidiano das crianças na segunda década do século XXI.

Durante a pesquisa de campo, observamos que o objeto (smartphone) não era completamente estranho da rotina dos bebês objetos dessa pesquisa. Eles sabiam que os botões e toques causavam reações no objeto, alguns sabendo inclusive interpretar seu uso como telefone, um meio de comunicação. A principio alguns bebês tiveram dificuldade de compreender que o objeto de exploração que se propunha era o livro digital (aplicativo) em nível de software e não o instrumento utilizado (smartphone) em todas suas funções e possibilidades.

Verificamos que além das habilidades motoras adquiridas de forma heurística, de forma paralela se desenvolve a linguística da criança, sem que o adulto necessite intervir de forma direta, se oportunizar a criança o contato orientado com livros digitais. Concluímos aqui, que baseada em observações por um relativo período de tempo e fundamentada em teorias da linguagem e pesquisas modernas em tecnologia e educação, que os livros digitais como objetos carregados de sentidos, contido de textos nos mais diferentes gêneros e tipos contribuem de forma significativa para a aquisição da linguagem em bebês.

Destacamos, contudo, que os livros digitais em língua portuguesa disponíveis nos repositórios de download são adequadas a outras faixas etárias, mais maduras e com mais ritmo de leitura e abstração. Em dezenas de livros que baixamos e pesquisamos as histórias são longas, com ênfase em detalhes e estrutura bem complexa tanto nos textos narrados, escritos ou visuais. Consideramos que estes livros são interessantes para crianças com 3 anos ou mais.

No decorrer da pesquisa não encontramos no idioma português um livro digital que fosse adequado pedagogicamente aos bebês, mas concluímos que com fomento de instituições públicas e privadas interessadas em pesquisas e projetos inovadores nas tecnologias e educação tais aplicativos podem ser 
produzidos com custo baixo e de maneira fidedigna às propostas para a faixa etária.

\section{Referencias}

ARIÈS, Philippe. (1981). História Social da Criança e da Família. 1 ed. Rio de Janeiro: Zahar Editores.

BAKHTIN, M. (1986). Marxismo e filosofia da linguagem: problemas fundamentais do método sociológico na ciência da linguagem. São Paulo: Hucitec.

(2003) Estética da Criação Verbal. 4. ed. São Paulo: Martins Fontes.

BRASIL. Insumos para o debate 2 - Emenda Constitucional n. ${ }^{\circ}$ 59/2009 e a educação infantil: impactos e perspectivas. São Paulo: Campanha Nacional pelo Direito à Educação, 2010a

BRASIL. Estatuto da criança e do adolescente: Lei n. 8.069, de 13 de julho de 1990, Lei n. 8.242, de 12 de outubro de 1991. - 3. ed. - Brasília : Câmara dos Deputados, Coordenação de Publicações, 2001.

BRASIL. Lei de Diretrizes e Bases da Educação Brasileira, Lei no 9394/96, (LDB), MEC.

BRASIL. Referencial Curricular para a Educação Infantil (RCNEI), MEC/SEF. Vol 1, 1988.

CAMPOS, R. F. Trabalho docente e formação de professores da educação infantil. Disponível em $<$ http://www.gepeto.ced.ufsc.br/arquivos/redestradoros elane.pdf $>$

COELHO. Nelly Novaes. (2000). Literatura infantil: teoria, análise, didática. São Paulo: Moderna.

GOLDSCMIED, Elinor e JACKSON, Sonia. (2006). Educação de 0 a 3 anos: o atendimento em creche. 2 ed. Porto Alegre: Grupo A.

GRATIOT-ALFANDÉRY, Hélène. (2010). Henry Wallon. Recife: Fundação Joaquim Nabuco, Editora Massangana.

FELDMAN, S. Shirley, SEARS, Robert R. As Sete Idades do Homem / trad. Alvaro Cabral. 2 ed. Rio de Janeiro: Zahar Editores, 1981.

FERRAREZI JUNIOR, Celso. (2008). Semântica para a educação básica. São Paulo: Parábola Editorial.

FREUD, S. (1976). Três Ensaios sobre as teorias da sexualidade (J.Salomão, Trad.). Edição Standard Brasileira das Obras Psicológicas completas de Sigmund Freud (Vol. VII ). Rio de Janeiro: Imago.

MORAN, José Manuel. (1995). Novas tecnologias e o reencantamento do mundo. Rio de Janeiro: Revista Tecnologia Educacional.

MOUZA, C. Using technology to enhance early childhood learning: The 100 days of school project. Educational Research and Evoluation. 2005. Disponível em: $<$ https://diagnosisfall2010.wikispaces.com/file/view/te ch+and+motiv.pdf $>$

MOSS, Peter. Qual o futuro da relação entre Educação Infantil e Ensino Obrigatório? Cadernos de Pesquisa. v.41 n.142. São Paulo: FCC, jan./abr. 2011.

MUNARI. Alberto. (2010). Jean Piaget. Recife: Fundação Joaquim Nabuco, Editora Massangana.

OLIVEIRA, J. (org.). (1988). Constituição da República Federativa do Brasil. São Paulo: Saraiva.
PALANGA, Isilda Campaner. Desenvolvimento e aprendizagem em Piaget e Vygotsky: a relevância do social. 3 ed. São Paulo: Summus, 2001.

PAPALIA, Diane E. (2006). Desenvolvimento Humano. trad. Daniel Bueno. 8 ed. Porto Alegre: Artmed.

PARREIRAS, Ninfa. (2012) Do ventre ao colo, do som à literatura. Belo Horizonte, RHJ.

PIAGET, J. (1970). A Construção do Real na Criança. Rio de Janeiro: Zahar.

(1976). Equilibração das Estruturas Cognitivas. Rio de Janeiro: Zahar.

PRENSKY, Marc. Digital Natives, Digital Immigrants. MCB University Press, 2001. Disponível em: $<$ http://www.marcprensky.com/writing/Prensky $\% 2$ $0 \% 20$ Digital $\% 20$ Natives, $\% 20$ Digital $\% 20$ Immigrants $\%$ 20-\%20Part1.pdf>

REYES, Yolanda. (2010). A casa imaginária: leitura e literatura na primeira infância. 1 ed. São Paulo: Global.

ROHRS, HERMANN. (2010). Maria Montessori. Recife: Fundação Joaquim Nabuco, Editora Massangana.

TALLAY, S., LANCE, D. F., LEE, T.R. Childreen, storybooks and computers. Reading horizons. 1997. Disponível em: $<$ http://scholarworks.wmich.edu/cgi/viewcontent.cgi?ar $\underline{\text { ticle}=1255 \& \text { context }=\text { reading_horizons }>}$

VYGOTSKY, L. S. (1996). A formação social da mente. Rio de Janeiro: Martins Fontes.

(1998). Pensamento e Linguagem.

Rio de Janeiro: Martins Fontes.

WALLON, H. Evolução psicológica da criança. São Paulo: Martins Fontes, 2007. 